\title{
PENGARUH LIFE STYLE, BRAND IMAGE DAN PROMOSI TERHADAP KEPUTUSAN PEMBELIAN PRODUK PERSONAL CARE DI PT EASTON KALERIS INDONESIA CABANG PADANG (Studi pada mahasiswa STIE “KBP' Padang)
}

\author{
Reni Febriani, Febsri Susanti \\ Sekolah Tinggi Ilmu Ekonomi "KBP" \\ febsrisusanti@akbpstie.ac.id
}

\begin{abstract}
The purpose of this study is to find out how the influence of life style, brand image and promotion of purchasing decision of personal care product in Pt Easton Kaleris Indonesia branch of Padang. The research method used is quantitative research. The sampling technique used is the sample size technique is purposive sampling. So from the population is taken a sample of 100 respondents. Data analysis techniques used are validity test, classical assumption test, multiple linear regression test, $F$ test and $T$ test. Based on multiple regression analysis, life style, brand image and promotion toward personal care product purchase decision in PT Easton Kaleris Indonesia. From the results of persial emerged life style and brand image significantly influence purchasing decisions, the value of significance produced $<0.005$. While the promotion variable does not affect the purchase decision because the value of significance is generated $>0.005$.
\end{abstract}

Keywords: life style, Brand Image, promotional buying decision

\section{PENDAHULUAN}

Dewasa ini kemajuan teknologi dan informasi yang menuju kearah globalisisi komonikasi dirasakan cenderung berpengaruh langsung terhadap tingkat peradapan masyarakat dan bangsa. Kita semua menyadari bahwa perkembangan teknologi informasi akhir akhir ini bergerak sangat pesat dan telah menimbulkan dampak positif maupun negatif terhadap tata kehudupan masyarakat diberbagai negara. Kemajuan bidang informasi membawa kita memasuki abad revolusi komonikasi. Apabila globalisasi diartikan sebagai perkembangan kebudayaan manuasia maka globalisasi informasi dan komonikasi yang muncul kerena perkembangan teknologi komonikasi diartikan sebagai teknologi elektronika yang mampu mendukung percepatan dan peningkatan kualitas informasi, selain itu teknologi mempermudah perusahaan perusahaan manufakturing, dagang dan jasa berupaya menjual citra perusahaan tersebut kemasyarakat luas. Makin tingginya teknologi makin tinggi tingkat persaingan anatar perusahaan oleh karena itu perusahaan harus mem[unyai strategi pemasaran yang khusus agar dapat mengadapi persaingan tersebut. 
Selain gaya hidup konsep diri juga mempengaruhi individu dalam mengambil keputusan. Memiliki brand image yang kuat merupakan suatu keharusan bagi setiap perusahaan karena citra merek merupakan aset perusahaan yang cukup berharga, dibutuhkan kerja keras dan waktu yang cukup lama untuk membuat reputasi dan citra suatu merek. Perusahaan menggunakan promosi untuk memicu transaksi sehingga konsumen mau membeli merek tertentu serta mendorong tenaga penjual untuksecara agresif menjualnya. Dengan promosi diharapkan konsumen mau mencoba produk tersebut. Keputusan pembelian konsumen terutama merek yang mengikuti perkembangan zaman dapat didasari oleh faktor perilaku konsumen yang cenderung berperilaku efektif yaitu perilaku yang dipengaruhi oleh suatu perasaan yang timbul oleh suatu keadaan tertentu. Pembelian produk personal care timbul ketika seseorang konsumen mengalami dorongan sekita sangat kuat dan mengikuti idolanya. Mereka lebih meniru apa yang lagi menjadi trend bagi idolanya maupun rata rata masyarakat yang menggunakanya. Pada saat musim bola maka apapun produk yang berkaitan dengan pemain bola pasti akan diburu oleh konsumen.

Perumusan Masalah

1. Apakah life style berpengaruh terhadap keputusan pembelian produk personal care di PT Easton Kaleris Indonesia?

2. Apakah Brand Image berpengaruh terhadap keputusan pembelian produk personal care di PT Easton Kaleris Indonesia?

3. Apakah Promosi berpengaruh terhadap keputusan pembelian produk personal care di PT Easton Kaleris Indonesia?

Tujuan Penelitian

1. Untuk menguji dan menganalisis pengaruh Life Style terhadap keputusan pembelian produk personal care di PT Easton Kaleris Indonesia cabang Padang.

2. Untuk menguji dan menganalisis pengaruh Brand Image terhadap keputusan pembelian produk personal care di PT Easton Kaleris Indonesia cabang Padang.

3. Untuk menguji dan menganalisis pengaruh Promosi terhadap keputusan pembelian produk personal care di PT Easton Kaleris Indonesia cabang Padang.

\section{LANDASAN TEORI}

\section{Life Style}

Life style diartikan sebagai cara hidup yang diidentifikasi oleh bagaimana orang menghabiskan waktu mereka (aktivitas) apa yang mereka anggap penting dalam lingkunganya (keterkaitan) dan apa yang mereka pikirkan tentang diri mereka sendiri dan dunia sekitarnya ( Nugroho, $2003: 148$ )

\section{Brand Image}

Menurut Tjiptono (2008 : 104) merek merupakan nama, istilah, tanda, simbol atau lambang, desain, warna, gerak atau kombinasi atribut atribut produk lainya yang di harapkan dapat memberikan identitas dan deferensiasi terhadap produk pesaing. 


\section{Promosi}

Dharmesta (2008 : 107) menyatakan bahwa promotion mix adalah kombinasi strategi yang paling baik dari variabel variabel periklanan, personal selling, dan alat promosi lainya yang semuanya direncanakan untuk mencapai tujuan program penjualan. Meskipun secara umum promosi memiliki fungsi yang sama, tetapi bentuk tersebut dapat dibedakan berdasarkan tugas tugas khususnya.

\section{Keputusan Pembelian}

Kotler (2008 : 109) menyebutkan keputusan konsumen adalah sebuah proses yang dilakukan konsumen dalam melakukan pembelian sebuah produk atau jasa.

\section{METODE PENELITIAN \\ Jenis Penelitian}

jenis penelitian yang digunakan dalam penelitian ini adalah kuantitatif research adalah penelitian yang berlandaskan pada filsafat positvme, digunakan untuk meneliti pada populasi atau sampel tertentu, pengumpulan data menggunakan instrumen penelitian serta analisis data bersifat kuantitatif statistik dengan tujuan untuk menguji hipotesis yang telah ditetapkan (sugiyono, 2009:8)

Populasinya adalah semua pria mulai dari usia 2030 tahun di kota Padang yang membeli produk personal care merek "Barcelona " . maka jumlah sampel yang akan digunakan dalam penelitian ini adalah sebanyak 100 responden. Dalam penelitian ini mendorong peneliti mengunakan metode kuantitatif.

\section{Teknik Analisi Data}

\section{Uji Validitas}

Uji validitas dalam penelitian ini digunakan untuk menguji kevalidan kuisioner. Validitas menunjukan sejauh mana ketepatan dan kecermatan suatu alat ukur dalam melakukan fungsi ukurnya ( Azwar, 2003 ). Penelitian ini dilakukan dengan bantuan program spss untuk menentukan nomor nomor yang valid dan yang gugur. Kriteria penilaianya adalah :

a. Apabila $\mathrm{r}$ hitung $>\mathrm{r}$ tabel ( pada taraf signifikansi $5 \%$ ), maka dapat dikatakan item kuisioner tersebut valid.

b. Apabila $\mathrm{r}$ hitung $<\mathrm{r}$ tabel ( pada taraf signifikansi $5 \%$ ), maka dapat dikatakan item kuisioner tersebut tidak valid.

\section{Analisis Reliabilitas}

Reliabilitas adalah sebuah indeks yang menunjukan sejauh mana hasil suatu pengukuran dapat dipercaya. Cara yang digunakan dalam menguji reliabilitas kuisioner adalah dengan menggunakan rumus koefisien cronbach alpha. Pada penelitian ini digunakan nilai 0,6 dengan asumsi bahwa daftar pertanyaan yang diuji akan reliabel dengan nilai cronbrach alpha $=0,6$.

Analisi Deskriptif

Untuk mendapatkan rata rata skor masing masing indikator dapat dipakai rumus sebagai berikut :

$$
\text { Rata rata skor }=\frac{F 1 x b s}{n}
$$

Keterangan : 
$\mathrm{F} 1=$ jumlah total skor responden jawaban

Bs $=$ skala likert $1-5$

$\mathrm{N}=$ jumlah responden

Uji Asumsi Klasik

\section{a. Uji Normalitas}

Uji distribusi normal adalah uji untuk mengukur apakah data yang didapatkan memiliki distribusi normal yang diambil dari populasi. Berdasarkan pengalaman empires dari beberapa pakar statistik data yang banyaknya lebih dari 30 angka $(\mathrm{n}>30)$. Maka sudah dapat diasumsikan berdeistribusi normal.

\section{b. Uji multikoliniaritas}

Uji multikoliniaritas bertujuan untuk menguji apakah model regresi ditemukan adanya korelasi antara variabel bebas. Uji multikoliniaritas ditemukan adanya korelasi antara variabel bebas. Uji multikoliniaritas dilakukan dengan melihat nilai variance inflation (VIF). Uji multikoliniaritas ini bertujuan untuk menguji apakah dalam model regresi ditemukan adanya korelasi antara variabel bebas.

\section{c. Uji Heteroskedastisitas}

Bertujuan untuk menguji apakah dalam model regresi terjadi ketidaksamaan variance dari residual suatu pengamatan lain. Alat uji yang digunakan adalah uji Glejser, Uji park, Uji white. Karakteristik pengujianya adalah apabila $\mathrm{t}$ hitung $<\mathrm{t}$ tabel, maka antara variabel bebas tidak terkena heteroskedastisitas terhadap nilai nilai residu lain atau residual model regresi ini adalah homogeny demikian sebaliknya.

\section{Analisi Regresi Linear Berganda}

Teknik analisis regresi berganda digunkan untuk mengetahui pengaruh life style, brand image dan promosi terhadap keputusan pembelian produk personal care. Persamaan regresi berganda yang digunakan adalah :

$Y=a+b_{1} X_{1}+b_{2} X_{2}+b_{3} X_{3}+e$

Dimana :

$\mathrm{Y}=$ Keputusan Pembelian

$\beta 0=$ Konstanta

$\beta 1 \beta 2 \beta 3=$ Koefisien Regresi

$\mathrm{X}_{1}=$ Variabel Life Style

$\mathrm{X}_{2}=$ Variabel Brand Image

$\mathrm{X}_{3}=$ Variabel keputusan Pembelian

\section{Uji F}

Uji F dilakukan untuk menguji hipotesis secara simultan. Dalam hal ini menguji pengaruh Life Style, Brand Image dan Promosi terhadap keputusan pembelian produk personal care. Prosedur pengujianya adalah :

a. Jika nilai $\mathrm{F}$-hitung $>\mathrm{F}$-tabel, maka variabel Brand image, gaya hidup dan promosi secara simultan ( bersama sama) berpengaruh terhadap keputusan pembelian produk personal care merek “ Barcelona".

b. Jika nilai F-hitung < F-tabel, maka variabel life style, brand image dan promosi secara simultan (bersama sama) tidak berpengaruh terhadap keputusan pembelian produk personal care merek “" Barcelona". 


\section{Uji T}

Uji T dilakukan untuk menguji hipotesis persial (sendiri sendiri). Dalam hal ini menguji pengaruh life style, brand image dan promosi terhadap keputusan pembelian produk personal care merek "Barcelona" prosedur pengujianya adalah : 1. Jika nilai t-hitung > t-tabel, maka variabel life style, brand image dan promosi secara persial (sendiri sendiri) berpengaruh terhadap keputusan pembelian produk personal care merek "Barcelona".

2. Jika nilai t-hitung < t-tabel, maka variabel life style, brand image dan promosi secara persial (sendiri sendiri) tidak berpengaruh terhadap keputusan pembelian produk personal care merek "Barcelona".

\section{Uji $\mathbf{R}^{2}$}

Ghozali (2009), koefisien determinasi pada intinya mengukur seberapa jauh kemampuan sebuah model dalam menerangkan variasi variabel dependen. Uji ini bertujuan untuk menetukan proporsi atau presentase total variasi dalam variabel terikat yang diterangkan oleh variabel bebas. Apabila analisi yang digunakan adalah regresi sederhana , maka yang digunakan adalah nilai $\mathrm{R}$ square, namun apabila analisi yang digunakan adalah regresi berganda, maka yang digunakan adalah Adjusted R Square.

Hasil perhitungan Adjusted $\mathrm{R}^{2}$ dapat dilihat pada output Model Summary. Pada kolom Adjusted $\mathrm{R}^{2}$ dapat diketahui berapa persentase yang dapat dijelaskan oleh variabel variabel bebas terhadap variabel terikat, sedangkan sisanya dipengaruhi atau dijelaskan oleh variabel variabel lain yang tidak dimasukan dalam model penelitian.

\section{PEMBAHASAN DAN HASIL PENELITIAN}

\section{Hasil Uji Validitas}

Uji validitas digunakan untuk mengukur sah atau tidak sahnya suatu kuesioner. Dasar pengambilan keputusan yang digunakan adalah melakukan uji signifikasi dengan membandingkan nilai $r$ hitung dengan $r$ tabel. Untuk sampel sekitar 100, nilai $r$ tabel $=0,195$. Uji ini dilakukan manakala butir pertanyaan lebih dari 1 .

Pengambilan keputusan uji validitas :

- Bila nilai $r$ hitung $>r$ tabel, maka item pertanyaan valid

- Bila nilai $r$ hitung $<\mathrm{r}$ tabel, maka item pertanyaan tidak valid

Pengujian validitas selengkapnya dapat dilihat pada tabel berikut ini:

Tabel 1

Uji Validitas Life Style

\begin{tabular}{|c|c|c|c|}
\hline No Item & $r_{\text {hit }}$ & $r_{\text {tabel }} 5 \%(100)$ & Keterangan \\
\hline 1 & 0,662 & 0,195 & Valid \\
\hline 2 & 0,765 & 0,195 & Valid \\
\hline 3 & 0,833 & 0,195 & Valid \\
\hline 4 & 0,861 & 0,195 & Valid \\
\hline 5 & 0,824 & 0,195 & Valid \\
\hline 6 & 0,814 & 0,195 & Valid \\
\hline 7 & 0,826 & 0,195 & Valid \\
\hline 8 & 0,717 & 0,195 & Valid \\
\hline
\end{tabular}

Sumber : data primer yang diolah, 2018 
Tabel 2

Hasil uji Validitas Brand Image

\begin{tabular}{|c|c|c|c|}
\hline No Item & $r_{\text {hit }}$ & $r_{\text {tabel }}$ 5\% $(100)$ & Keterangan \\
\hline 1 & 0,723 & $\mathbf{0 , 1 9 5}$ & Valid \\
\hline 2 & 0,749 & $\mathbf{0 , 1 9 5}$ & Valid \\
\hline 3 & 0,856 & $\mathbf{0 , 1 9 5}$ & Valid \\
\hline 4 & 0,770 & $\mathbf{0 , 1 9 5}$ & Valid \\
\hline 5 & 0,741 & $\mathbf{0 , 1 9 5}$ & Valid \\
\hline 6 & 0,633 & $\mathbf{0 , 1 9 5}$ & Valid \\
\hline
\end{tabular}

Sumber : data primer yang diolah, 2018

Tabel 3

Hasil uji Validitas Promosi

\begin{tabular}{|c|c|c|c|}
\hline No Item & $r_{\text {hit }}$ & $r_{\text {tabel }} 5 \%(100)$ & Keterangan \\
\hline 1 & 0,672 & $\mathbf{0 , 1 9 5}$ & Valid \\
\hline 2 & 0,576 & $\mathbf{0 , 1 9 5}$ & Valid \\
\hline 3 & 0,628 & $\mathbf{0 , 1 9 5}$ & Valid \\
\hline 4 & 0,682 & $\mathbf{0 , 1 9 5}$ & Valid \\
\hline 5 & 0,569 & $\mathbf{0 , 1 9 5}$ & Valid \\
\hline 6 & 0,638 & $\mathbf{0 , 1 9 5}$ & Valid \\
\hline 7 & 0,509 & $\mathbf{0 , 1 9 5}$ & Valid \\
\hline 8 & 0,573 & 0,195 & Valid \\
\hline
\end{tabular}

Sumber : data primer yang diolah, 2018

Tabel 4

Hasil uji Validitas Keputusan Pembelian

\begin{tabular}{|c|c|c|c|}
\hline \multirow{2}{*}{ No Item } & $r_{\text {hit }}$ & $r_{\text {tabel }} 5 \%(100)$ & Keterangan \\
\hline 1 & 0,630 & $\mathbf{0 , 1 9 5}$ & Valid \\
\hline 2 & 0,692 & $\mathbf{0 , 1 9 5}$ & Valid \\
\hline 3 & 0,769 & $\mathbf{0 , 1 9 5}$ & Valid \\
\hline 4 & 0,759 & $\mathbf{0 , 1 9 5}$ & Valid \\
\hline 5 & 0,702 & $\mathbf{0 , 1 9 5}$ & Valid \\
\hline 6 & 0,256 & $\mathbf{0 , 1 9 5}$ & Valid \\
\hline
\end{tabular}

Sumber : data primer yang diolah, 2018

Dari hasil dapat dijelaskan nilai $r$ hitung lebih besar dari $r$ tabel $(0,195)$ dengan demikian dapat disimpulkan bahwa semua item dalam indikator variabel life style, brand image, promosi dan keputusan pembelian adalah valid.

\section{Hasil Uji Realibitas}

Uji reliabilitas digunakan untuk mengukur konsistensi dari suatu variabel. Butir pertanyaan dalam variabel dikatakan reliabel atau terpercaya apabila jawaban responden adalah konsisten atau stabil dari waktu ke waktu. Suatu konstruk atau variabel dikatakan reliabel jika nilai alpha lebih besar dari $r_{\text {tabel }}$ $(0,195)$. 
Tabel 5

Hasil Uji Reabilitas

\begin{tabular}{|c|c|c|c|}
\hline Variabel & $\mathrm{r}_{\mathrm{xy}}$ & $r_{\text {tabel }} 5 \%(100)$ & Keterangan \\
\hline $\mathrm{X} 1$ & 0,911 & 0,195 & Reliabel \\
\hline $\mathrm{X} 2$ & 0,841 & 0,195 & Reliabel \\
\hline $\mathrm{X} 3$ & 0,755 & 0,195 & Reliabel \\
\hline $\mathrm{Y}$ & 0,711 & 0,195 & Reliabel \\
\hline
\end{tabular}

Sumber : data primer yang diolah, 2018

Berdasarkan tabel diatas dapat diketahui bahwa masing-masing variabel antara variabel life style, brand image, promosi dan keputusan pembelian ternyata diperoleh nilai alpha lebih besar dari $r_{\text {tabel }}(0,195)$. Dengan demikian, maka hasil uji reabilitas terhadap keseluruhan variabel adalah reliabel.

\section{Hasil Uji Normalitas Kolmogorov Smirnov}

Pengujian normalitas dilakukan untuk mengetahui normal tidaknya suatu distribusi data. Hal ini penting diketahui karena berkaitan dengan ketepatan pemilihan teknik uji yang akan digunakan. Uji normalitas data dalam penelitian ini menggunakan uji Kolmogorov-Smirnov (K-S) one sample.

Tabel 6

\section{One-Sample Kolmogorov-Smirnov Test}

\begin{tabular}{|c|c|c|}
\hline & & Unstandardized Residual \\
\hline $\mathrm{N}$ & & 100 \\
\hline \multirow[t]{2}{*}{ Normal Parameters ${ }^{\mathrm{a}}$} & Mean & .0000000 \\
\hline & Std. Deviation & 1.92621279 \\
\hline \multirow[t]{3}{*}{ Most Extreme Differences } & Absolute & .070 \\
\hline & Positive & .035 \\
\hline & Negative & -.070 \\
\hline Kolmogorov-Smirnov Z & & .695 \\
\hline Asymp. Sig. (2-tailed) & & .719 \\
\hline
\end{tabular}

a. Test distribution is Normal.

Sumber : data primer yang diolah, 2018

Berdasarkan hasil pengolahan data yang telah dilakukan untuk uji normalitas dengan menggunakan Kolmogorov-Smirnov(K-S) one sample hasil uji normalitas diketahui nilai signifikasi 0,719>0,05, maka dapat disimpulkan bahwa nilai residual berdistribusi normal.

\section{Hasil Uji Heterokedastisitas dengan uji gletser}

Uji Heteroskedastisitas digunakan untuk menguji apakah dalam suatu model regresi terdapat kesamaan atau ketidak samaan varians antara pengamatan yang satu dengan pengamatan yang lainnya, dalam penelitian ini menggunakan uji statistik dengan Uji Glejser melalui regresi nilai absolute residual dengan variabel independennya. Nilai sig dibandingkan dengan 0.05. hasil statistik dapat dilihat di tabel di bawah ini. 
Tabel 7

Hasil uji heteroskedastisitas dengan uji gletser

Coefficients $^{\mathrm{a}}$

\begin{tabular}{|c|c|c|c|c|c|}
\hline \multirow[b]{2}{*}{ Model } & \multicolumn{2}{|c|}{ Unstandardized Coefficients } & \multirow{2}{*}{$\frac{\text { Standardized Coefficients }}{\text { Beta }}$} & \multirow[b]{2}{*}{$\mathrm{t}$} & \multirow[b]{2}{*}{ Sig. } \\
\hline & B & Std. Error & & & \\
\hline $1 \quad$ (Constant) & 2.990 & 1.165 & & 2.565 & .012 \\
\hline Life style & -.007 & .031 & -.029 & -.226 & .821 \\
\hline Brand Image & -.063 & .048 & -.182 & -1.313 & .192 \\
\hline Promosi & .004 & .042 & .012 & .104 & .917 \\
\hline
\end{tabular}

a. Dependent Variable: RES2

Sumber : data primer yang diolah, 2018

Berdasarkan hasil uji heteroskedastisitas melalui uji Glejser pada tabel di atas dapat dlihat bahwa sig. pada masing-masing variabel bernilai lebih dari 0.05. dan dapat dikatakan bahwa hal ini menunjukkan tidak terjadi heteroskedastisitas dalam model

regresi pada penelitian ini. dan variabel-variabel independen dapat dinyatakan tidak mengalami heteroskedastisitas.

\section{Hasil Uji Multikolienaritas}

Uji multikolinearitas bertujuan untuk menguji apakah pada model regresi ditemukan adanya korelasi antar variabel independen. Jika terjadi korelasi, maka dinamakan terdapat problem Multikolinearitas. Model regresi yang baik seharusnya tidak terjadi korelasi di antara variabel independen.

Deteksi tidak adanya Multikolinearitas yakni dengan melihat besaran VIF (Variance Inflation Factor) dan Tolerance (Ghozali, 2006):

- Mempunyai nilai VIF $<10$

- Mempunyai angka TOLERANCE $>10 \%$

Mengacu pada kedua pendapat di atas maka berdasarkan hasil penelitian yang telah dilakukan dapat diperoleh nilai :

\section{Tabel 8}

Hasil Uji Multikolinearitas

\section{Coefficients $^{\mathrm{a}}$}

\begin{tabular}{|c|c|c|c|c|c|c|c|}
\hline \multirow[b]{2}{*}{ Model } & \multicolumn{2}{|c|}{$\begin{array}{l}\text { Unstandardized } \\
\text { Coefficients }\end{array}$} & \multirow{2}{*}{$\begin{array}{c}\text { Standardized } \\
\text { Coefficients }\end{array}$} & \multirow[b]{2}{*}{$\mathrm{T}$} & \multirow[b]{2}{*}{ Sig. } & \multicolumn{2}{|c|}{ Collinearity Statistics } \\
\hline & B & Std. Error & & & & Tolerance & VIF \\
\hline 1 (Constant) & 7.640 & 2.041 & & 3.744 & .000 & & \\
\hline Life style & .241 & .054 & .385 & 4.419 & .000 & .614 & 1.630 \\
\hline $\begin{array}{l}\text { Brand } \\
\text { Image }\end{array}$ & .421 & .084 & .473 & 5.021 & .000 & .524 & 1.910 \\
\hline Promosi & -.066 & .073 & -.071 & -.907 & .367 & .767 & 1.304 \\
\hline
\end{tabular}

a. Dependent Variable: Keputusan

Pembelian

Sumber : data primer yang diolah, 2018 
Tabel 9

Hasil dan Kesimpulan

\begin{tabular}{|c|c|c|c|}
\hline V & Tolerance & VIF & Kriteria \\
\hline X1 & 0,614 & 1.630 & No multikolienaritas \\
\hline X2 & 0,524 & 1.910 & No multikolienaritas \\
\hline X3 & 0,767 & 1.304 & No multikolienaritas \\
\hline
\end{tabular}

Sumber : data primer yang diolah, 2018

Analisis Regresi linear berganda

Berdasarkan perhitungan regresi berganda antara life style (X1), brand image (X2) dan promosi (X3) terhadap keputusan pembelian (Y) dengan dibantu program SPSS dalam perhitungannya dapat diperoleh hasil sebagai berikut :

Tabel 10

Hasil uji regresi linear berganda

Coefficients $^{\mathbf{a}}$

\begin{tabular}{|c|c|c|c|c|c|}
\hline \multirow[b]{2}{*}{ Model } & \multicolumn{2}{|c|}{$\begin{array}{l}\text { Unstandardized } \\
\text { Coefficients }\end{array}$} & \multirow{2}{*}{$\begin{array}{c}\begin{array}{c}\text { Standardized } \\
\text { Coefficients }\end{array} \\
\text { Beta }\end{array}$} & \multirow[b]{2}{*}{$\mathrm{t}$} & \multirow[b]{2}{*}{ Sig. } \\
\hline & B & Std. Error & & & \\
\hline (Constant) & 7.640 & 2.041 & & 3.744 & .000 \\
\hline Life style & .241 & .054 & .385 & 4.419 & .000 \\
\hline Brand Image & .421 & .084 & .473 & 5.021 & .000 \\
\hline Promosi & -.066 & .073 & -.071 & -.907 & .367 \\
\hline
\end{tabular}

a. Dependent Variable: Keputusan Pembelian

Sumber : data primer yang diolah, 2018

Berdasarkan tabel di atas dapat diperoleh model persamaan regresi sebagai berikut

$\mathrm{Y}=\alpha+\beta 1 X 1+\beta 2 X 2+\beta 3 X 3$

$Y=7,640+0,241 X 1+0,421 X 2-0,066 X 3$

Artinya :

1. Nilai $\mathrm{a}=7,640$ artinya jika life style, brand image dan promosi tidak adamaka keputusan pembelian produk barcelona akan tetap sebesar 7,640 .

2. Nilai $\mathrm{X} 1=0,241$ artinya Koefisien regresi life style menunjukkan arah positif. Hal ini berarti jika life style meningkat maka keputusan pembelian produk barcelona akan meningkat sebesar 0,241.

3. Nilai $X 2=0,421$ artinya koefisien regresi brand imagemenunjukkan arah positif. Hal ini berarti jika brand image meningkat maka keputusan pembelian produk barcelona akan meningkat sebesar 0,421.

4. Nilai $\mathrm{X} 3=-0,066$ artinya koefisien regresi promosi menunjukkan arah negatif. Hal ini berarti jika promosi meningkat maka keputusan pembelian produk barcelona akan menurun sebesar 0,066 .

Berdasarkan persamaan regresi di atas, maka dapat dianalisis pengaruh variabel independen terhadap variabel dependen sebagai berikut :

Persamaan regresi linear berganda diketahui mempunyai nilai konstanta sebesar 7,640 Hal ini menunjukkan bahwa jika variabel independen diasumsikan dalam keadaan tetap, maka varibel dependen (keputusan pembelian) akan naik sebesar 7,640 \%. Untuk arah tanda signifikannya, variabel life style dan brand 
image mempunyai arah positif terhadap keputusan pembelian, sedangakan promosi mempunyai arah yang negatif terhadap keputusan pembelian.

\section{Uji koefisien regresi simultan (uji F)}

\section{Tabel 11}

Hasil uji koefisien regresi simultan (uji F) ANOVA $^{\mathrm{b}}$

\begin{tabular}{|c|c|c|c|c|c|}
\hline Model & Sum of Squares & Df & Mean Square & $\mathrm{F}$ & Sig. \\
\hline $1 \quad$ Regression & 455.431 & 3 & 151.810 & 39.676 & $.000^{\mathrm{a}}$ \\
\hline Residual & 367.319 & 96 & 3.826 & & \\
\hline Total & 822.750 & 99 & & & \\
\hline
\end{tabular}

a. Predictors: (Constant), Promosi , Life style, Brand Image

b. Dependent Variable: Keputusan Pembelian

Sumber : data primer yang diolah, 2018

Berdasarkan tabel di atas dapat diketahui nilai signifikan besesar 0,000 $<0,005$ yang dapat diartikan bahwa semua variabel independen mempunyai pengaruh yang signifikan secara bersama-sama terhadap variabel dependen (keputusan pembelian)

\section{Uji koefisien regresi secara parsial (uji T)}

Tabel 12

Hasil uji koefisien regresi secara parsial (uji T)

Coefficients $^{\mathrm{a}}$

\begin{tabular}{|c|c|c|c|c|c|c|}
\hline \multirow{2}{*}{\multicolumn{2}{|c|}{ Model }} & \multicolumn{2}{|c|}{$\begin{array}{l}\text { Unstandardized } \\
\text { Coefficients }\end{array}$} & \multirow{2}{*}{$\frac{\begin{array}{c}\text { Standardized } \\
\text { Coefficients }\end{array}}{\text { Beta }}$} & \multirow[b]{2}{*}{$\mathrm{t}$} & \multirow[b]{2}{*}{ Sig. } \\
\hline & & B & Std. Error & & & \\
\hline \multirow[t]{4}{*}{1} & (Constant) & 7.640 & 2.041 & & 3.744 & .000 \\
\hline & Life style & .241 & .054 & .385 & 4.419 & .000 \\
\hline & Brand Image & .421 & .084 & .473 & 5.021 & .000 \\
\hline & Promosi & -.066 & .073 & -.071 & -.907 & .367 \\
\hline
\end{tabular}

a. Dependent Variable: Keputusan Pembelian

Sumber : data primer yang diolah, 2018

Berdasarkan tabel uji parsial di atas dapat diketahui bahwa variabel life style dan brand image berpengaruh secara signifikan terhadap keputusan pembelian karena memiliki nilai signifikan $<0,005$, sedangkan varibael promosi tidak mempunyai pengaruh terhadap keputusan pembelian karena nilai signifikan $>0,005$.

\section{Uji determinasi $\left(R^{2}\right)$}

Tabel 13

Hasil uji determinasi $\left(R^{2}\right)$

Model Summary

\begin{tabular}{|l|l|r|r|r|}
\hline Model & R & R Square & Adjusted R Square & \multicolumn{2}{|c|}{ Std. Error of the Estimate } \\
\hline 1 & $.744^{\mathrm{a}}$ & .554 & .540 & 1.95608 \\
\hline
\end{tabular}

a. Predictors: (Constant), Promosi, Life style, Brand Image

Sumber : data primer yang diolah, 2018 
Berdasarkan tabel di atas dapat diketahui nilai Adjusted R Square sebesar 0,540. Dengan kata lain semua variabel indpenden (life style, brand image dan promosi) mampu menjelaskan variabel dependen (keputusan pembelian) sebesar $54 \%$, sedangkan sisanya $46 \%$ di pengaruhi oleh faktor-faktor lain yang tidak di ajukan dalam penelitian ini.

\section{PEMBAHASAN}

Dengan melibatkan sebanyak 100 orang responden, memberikan informasi mengenai pengaruh dari variable life style, brand image dan promosi terhadap keputusan pembelian. Dari tabel tersebut dapat diterangkan bahwa angka Adjusted R square sebesar 0,540 menunjukkan bahwa 54\% variabel keputusan pembelian dapat di jelaskan oleh variabel life style, brand image dan promosi. Sedangkan sisanya sebesar $46 \%$ dijelaskan oleh variabel lain.

Dari tabel uji validitas dapat diketahui bahwa variabel life style, brand image dan promosi serta keputusan pembelian mempunyai $r$ hitung yang lebih besar daripada alpha lebih besar dari $r_{\text {tabel }}(0,195)$, sehingga dapat dikatakan bahwa semua indikator pertanyaan yang digunakan dalam penelitian ini adalah valid.

Dari tabel uji reliabilitas dapat diketahui bahwa masing-masing variabel antara kualitas pelayanan, harga, lokasi dan kepuasan pelanggan diperoleh nilai alpha lebih besar darir tabel $(0,195)$. Dengan demikian, maka hasil uji reabilitas terhadap keseluruhan variabel adalah reliabel.

Dari tabel uji normalitas dengan menggunakan uji One-Sample Kolmogrov-Smirnov, terlihat bahwa nilai Kolmogrov-Smirnov untuk variabel residual sebesar 0,695 dan signifikan sebesar 0,719 di atas 0,05. Hal ini menunjukkan bahwa data residual terdistribusi normal., maka model regresi memenuhi asumsi normalitas. Dari tabel heteroskedastisitas melalui uji Glejser dlihat bahwa sig. pada masing-masing variabel bernilai lebih dari 0.05. dan dapat dikatakan bahwa hal ini menunjukkan tidak terjadi heteroskedastisitas dalam model regresi pada penelitian ini. dan variabel-variabel independen dapat dinyatakan tidak mengalami heteroskedastisitas.

Dari tabel multikolinearitas dapat diketahui bahwa nilai Variance Inflation Factor ( VIF ) dari masing masing variabel bebas lebih kecil dari angka 10, dan nilai tolerance lebih besar dari 0,1 . Sehingga dapat disimpulkan bahwa pada uji regresi tersebut tidak terdapat problem multikolinieritas, maka model yang ada layak untuk dipakai dalam penelitian ini.

Dari uji t diketahui bahwa nilai t hitung $>\mathrm{t}$ tabel dan tingkat signifikan < 0,05 untuk variabel life style dan brand image. Sehingga dapat disimpulkan bahwa variabel life style dan brand image secara parsial (sendiri-sendiri) berpengaruh terhadap keputusan pembelian, namun variabel promosi diketahui bahwa nilai $t$ hitung $<\mathrm{t}$ tabel dan tingkat signifikan $>0,05$, sehingga dapat di simpulkan bahwa variabel promosi secara parsial (sendiri-sendiri) tidak berpengaruh terhadap keputusan pembelian. Dari uji F juga di ketahui bahwa $\mathrm{F}$ hitung $>\mathrm{F}$ tabel dan tingkat signifikasi $<0,05$ sehingga dapat disimpulkan bahwa variabel life style, brand image dan promosi berpengaruh secara bersama-sama (simultan) terhadap keputusan pembelian. 


\section{PENUTUP}

\section{Kesimpulan}

Dari hasil pengujian hipotesis yang telah dilakukan maka dapat disimpulkan sebagai berikut :

1. Life style mempengaruhi keputusan pembelian konsumen secara signifikan dan positif pada produk personal care PT Easton Kaleris Indonesia cabang Padang.

2. Brand image mempengaruhi keputusan pembelian konsumen secara signifikan dan positif pada produk personal care PT Easton Kaleris Indonesia cabang Padang.

3. Promosi berpengaruh positif dan signifikan terhadap keputusan pembelian konsumen secara signifikan dan positif pada produk personal care PT Easton Kaleris Indonesia cabang Padang.

4. Berdasarkan hasil penelitian diperoleh $54 \%$ keputusan pembelian pada produk personal care PT Easton Kaleris Indonesia yang dapat dijelaskan oleh variabel life style, brand image dan promosi sedangkan sisanya sebesar $46 \%$ dijelaskan oleh variabel variabel yang tidak

Saran diteliti dalam penelitian ini.

Penelitian yang akan datang diharap menguji variabel-variabel lain yang mungkin mempengaruhi Minat Beli Konsumen.

1. Bagi peneliti-peneliti berikutnya yang ingin mengadakan penelitian serupa agar dapat mengembangkan hasil penelitian ini dengan mengakat objek penelitian pada perusahaan lainnya dengan jenis usaha yang berbeda.

2. Menambah variabel bebas selain life style, brand image dan promosi terhadap keputusan pembelian.

\section{DAFTAR PUSTAKA}

Amanah, D. dan H. P. M. S. (2013). Pengaruh gaya hidup dan promosi terhadap keputusan pembelian produk matahari plaza medan fair di kalangan mahasiswa fakultas ekonomi universitas negri medan. Plans, Penelitian Llmu Manajemen \& Bisnis, VIII(2), 1-6

Aziz, N. (2019). Pengaruh Atribut Produk Terhadap Minat Beli Sepeda Motor Honda Dealer Amanah Lubuk Alung. https://doi.org/10.17605/OSF.IO/BNDAE

Hidayati, R. R., \& Marlius, D. (2018). Aktivitas Promosi Dalam Meningkatkan Dana Pihak Ketiga Pada PT. Bank Perkreditan Rakyat (BPR) Batang Kapas Pesisir Selatan. https://doi.org/10.31227/osf.io/8dgqn

Marlius, D. (2017). Keputusan Pembelian Berdasarkan Faktor Psikologis Dan Bauran Pemasaran Pada PT. Intercom Mobilindo Padang. Jurnal Pundi. Volume 1. No. 1. Hal. 57-66. https://doi.org/10.31575/jp.v1i1.9 
Marlius, D. (2016). Pengaruh Bauran Pemasaran Jasa Terhadap Minat Nasabah Dalam Menabung Pada Bank Nagari Cabang Muaralabuh. https://doi.org/10.31227/osf.io/vdqgx

Mayliza, R. (2019). Pengaruh Citra Perusahaan (Corporate Image) Dan Penanganan Keluhan (Complaint Handling) Terhadap Loyalitas Pelanggan (Loyality) Natasha Skin Care Di Kota Padang. https://doi.org/10.17605/OSF.IO/DF9XJ

Safitri, R. N., \& Marlius, D. (2017). Penerapan E-Banking Dalam Meningkatkan Jasa Dan Layanan Perbankan Di PT. Bank Rakyat Indonesia Cabang Padang. https://doi.org/10.31227/osf.io/gkv8t

Susanti, F. (2014). Pengaruh Tarif Iklan Terhadap Pendapatan Pada PT. Radio Swara Carano Batirai Indah Batusangkar. https://doi.org/10.31227/osf.io/dy863

Susanti, F. (2015). Pengaruh Bauran Promosi Terhadap Keputusan Klien Dalam Memilih Radio Carano Sebagai Media Promosi Iklan. https://doi.org/10.31227/osf.io/b9ws7

Wijaya, M. H. P. (2013). Promosi, Citra Merek, dan Saluran Distribusi Pengaruhnya Terhadap Keputusan Pembelian Jasa Terminix di Kota Manado. JURNAL RISET EKONOMI, MANAJEMEN, BISNIS DAN AKUNTANSI. $\quad$ Retrieved from http://ejournal.unsrat.ac.id/index.php/emba/article/view/2578

Widayati, R. (2019). Promotional Activities And Services Bank Nagari Kambang Increase In Customer. https://doi.org/10.17605/OSF.IO/MYAVT. 